\title{
Educational space representation in cyberspace
}

\author{
Magomed M. Abdurazakov ${ }^{1, *}$, Yurii G. Korotenkov ${ }^{1}$, and Magomed G. Muhidinov ${ }^{2}$ \\ ${ }^{1}$ ISED RAE, Center of the Theory and Methodology of Teaching Mathematics and Computer Science, 105062, Moscow, Russia \\ ${ }^{2}$ DSINE, Chair of Higher Mathematics, Makhachkala, Russia
}

\begin{abstract}
The spatial representation problems of the educational sphere, of the information educational milieu, media milieu are analyzed; the problems of the media education, of Smarteducation, media competence and media culture of education subjects are examined. The descriptions of the educational cyberspace and interaction characteristics with the educational subjects in the context of modal logic are offered.
\end{abstract}

Educational space is a wide and multifaceted concept. It is an ordered representation of the real system, rather metasystem, education existing in a variety of forms and organizational structures. This is general education secondary, higher, tertiary and career development system, steadily expanding in modern information society. In the era of global informatization the distance learning becomes more available and in-demand. It is also different forms of self-education, provided by society's educational and socio-cultural resources and technologies of its informatization.

The general education structure has been thoroughly studied and substantiated with reference to the current sets of objective factors: the education conditions, the requirements for it - scientific, social, ideological, cultural, economic, technological, etc., as well as based on trends in education and its intestinal necessity. Therefore, it is relatively invariant accurate to changing the conditions and requirements themselves by the corresponding evolution. Nevertheless, as the education is social, then the subjective factor, subjectivism occurs in its organization and development. There may be revolutionary changes, affecting not only the structure, but also education system architecture not always obtaining the identical degree of positivity.

The spatial representation of the education sector is informative and, therefore, it is a part of the informational space in social and informational milieu. First, it includes the education subjects (carriers, distributors and recipients of educational information) forming the basic "dimension" of informational and educational space. The second "dimension" is built up by teaching techniques, information and educational resources, electronic and educational resources (IER and EER), the media milieu resources. The third "dimension" is built up by electronic technologies and communications. Each of these dimensions has its own representation in a variety of constant and variable "dimensions" with own relevance.
No less important "dimension" of the space is the science of education, pedagogy, and didactics. In the era of IT development when computer science concepts become general scientific notions, then they become a part of the pedagogics, subject methods. The education methodology becomes informational, pedagogic systems are actualized in pedagogical techniques. Consequently, the personal information culture including its information security culture, media competence and media culture turns into the subjects of pedagogics.

Another structure of the information educational space is a representation of the information educational space, IEE. IEE has already received a wide coverage in the pedagogical milieu, so we confined to the following characteristics:

Information educational milieu is a representation of the educational milieu in the information form, its image in the information resources, technologies, tutorial and management systems, expressed in a documented form and methodologically adapted to education. The main objective of the IEE is providing education transition to a new quality: to the state relevant to the information society.

Influenced by the universal telecommunications the IEE enlargement occurs due to the society media milie, containing digitized objects of its social culture (media objects), and supported by media resources and media technologies. Adapted and specialized media resources make up educational media milieu.

Media milieu on parity basis is formed by media information, media devices and media communication. In this case, information remains the main component of this triad: it is the starting point of social and cultural, educational and psychological impact. Media and communication merely provide, implement this impact. Thus the information in media milieu, the media information, acquires specific properties that are lost outside the media milieu.

Information competence of the subject is supplemented by its media competence, information 
culture - by media culture. Education moves into a new form, the state of media education the purpose of which is to build up media competences, subjects' media culture and education backed by them and multimedia information educational (MIE) resources. Consequently, media competence and media culture of the subjects may act both as a product and as intellectual means of education. They are also necessary for self-education and self-development [1].

Nowadays much emphasis is on the Smart-society as a form of information society and Smart-education. Media milieu and components forming it underlain Smart-environment, Smart-tools, Smart-resources. Correspondingly, the Smart-education outgrows media education through the effective use, adaptation and development of media education and its media resources. Smart-tools difference from media tools lies in the fact that they do not simply reproduce the media information under the control of a computer, but they themselves are capable of own and autonomous processing of Smart milieu information. Namely, Smart tool is an independent intelligent system capable of processing and converting media information autonomously in on-line mode. Smart-technology is a media technology that provides fulfilling these functions.

Media education and Smart-education are fundamentally new forms of education with a different structure, involving the division of academic labor, with different methodology, didactics and subjects' teaching techniques [2].

Further intellectualization of information and educational resources, electronic and educational resources (IER and EER) is implemented in media education and Smart-education that creates the symptoms of a fundamentally new educational media resource - cyber-resource, constituting cyber-education system together with the related cyber-technology. These cyber-resources and cyber systems generate educational cyberspace - system electronic virtual representation of information and educational space.

Owing to the development of informatization, globalization, telecommunications increasing public emphasis is paid to electronic and communication virtual world (ECVW) which, by virtue its derivative globality, is ordered, systematized and converted into a multi-dimensional space, cyberspace. This space is intellectual, and its intelligence is based on the human initial intelligence (natural) and artificial intelligence of formal systems.

Cyberspace is a product and means of informatization that provide optimal interaction with electronic virtual world; its abstract representation with an ordered set of dimensions allowing modeling and algorithmization of ways in any possible direction. This is a virtual world relation model, the signs of which are considered as dimensions along with expanding value sets.

Educational cyberspace is a specific part of the common cyberspace, having an educational purpose and characterized by targeted educational relationship with it. Consequently, internal relations, the educational cyberspace structure act as derived: they will be determined by its relationship with education subjects in terms of their effectiveness, rationality and safety.

Cyberspace, representing the real resources images and their relationships, are virtually and completely abstract. Therefore, it can be described as unreal. It "comes alive" only in the implementation of its actual backward and forward linkages with the person, in their mutual influence. Consequently, each subject of education, creating educational cyberspace with educational interaction, becomes its constitutive component and, therefore, the object of pedagogical research (in this guise).

Education Cyberspace consists of common cyberspace's elements, to which educational relationships are established, aimed at achieving the objectives of education and education subjects' personal development. In this regard, almost all the resources of society in cyberspace that have the potential positive effects (scientific, educational, social, cultural, ideological, and psychological) on the subject of education can be referred to the education cyberspace. However, specialized educational portals, adapted media resources, media electronic educational resources, intended for education and subject teaching, make up the constitutive part of education cyberspace.

Subject and educational cyberspace interaction meets the media information needs, creates derivative information and provides an information exchange. The point is not that the subjects create physically new worlds, expanding cyberspace. This is happened to be too, but it is not necessarily. The education subject takes, "assigns" part of this cyberspace, temporarily or permanently "prescribing" itself in it. The information and, accordingly, each element of the educational cyberspace, "taken into account" by the subject, become its possession, by which it is able physically to enjoy on its own. Another thing is that there are ethical and moral standards, the copyright and other information rights provisions, culture of use and references, etc. To do this requires for personal media culture.

The electronic world is an image of the real world, a kind of model, reflecting its properties and changing along with it. It cannot be completely independent as a derivative image, but it has long been living by its own laws (written and unwritten).

The real world is immense, not everything is accessible and achievable. The electronic world with its network connections is completely overlooked, everything is physically available. Nevertheless, it is the danger that if a person begins to feel himself or herself better and more comfortable than in the real world, so he or she could not adapt to the real world, or has psychological deviations - he or she became a virtual world prisoner. Largely, this danger is emerging spiritual and intelligent systems - the younger generation and students. However, unfortunately, this problem is related not only to them. When, for example, media milieu and cyber space culture is boiled down ethics in computer science textbook (or rather, to the etiquette) on the Internet, that is something to think about.

A person going into a virtual world begins to "grow roots" in it, improving, changing it at his or her 
discretion and building his or her subspace of it. Moreover, in general, it is easier than to change the real world. However, he or she is not always aware that any model has feedback, affecting the original object. Alternatively, even worse, he or she deliberately commits no righteous deeds, but this is a consequence of the lack of culture, personal information culture. In any case, once the negative changes occur in virtual world, they manifest and reproduce themselves immediately in the real world. Therefore, the "withdrawal" of a person into virtual world is dangerous to himself or herself and to society.

Furthermore, the following fact becomes increasingly important, due to the global virtual world and its growing influence on reality. Human logic is diverse; his every action is caused by personal knowledge, subjective, psychological, socio-cultural, pragmatic and other prerequisites. The necessity and possibilities, interests and responsibilities intervene in a dispute. The virtual world is simpler: the binary logic is here; so it is more accessible, and it is more comfortable. But then again, according to the law of reversed effect, the binary logic is reproduced in the real world, meanwhile at the level of "prisoners" and "breakers" of the virtual world. Nevertheless, this is a very dangerous phenomenon.

The man, carrying a black and white logic over the real world, identifies physical and logical possibilities. However, the real world laws determine the physical possibility, i.e. it is necessary. Nevertheless, a logical possibility cannot be thereof. In fact, the situation is even worse: a man with a black-and-white logic assumes a physical possibility (in his perception and logical) as truth, with all the ensuing negative consequences. All this is a particular hazard to the young subjects of education as merely constitutive information and psychological systems, students.

Plenty of cyberspace researchers relate it to modal logic, as the choice of any path and structure of any subspace in it is based on a variety of logical assessed values - necessities or chances, possibilities and impossibilities, their various combinations. This logic was proposed by Aristotle and K. Leibnitz, but it proved unclaimed for many years. Particularly, the Chinese scientist Liu Gang points out, "cyberspace, formed by a computer network, is nothing else than ... a tool for the study of our senses and the mind," [4]. Hence, the cyberspace interaction develops human knowledge and culture while the human culture and knowledge optimize this interaction. It means to the knowledge of the system that cyberspace, considered in the context of modal logic, allows to:

- Provide personal development of the educational subjects in a harmonious combination of knowledge and culture, "reason and affections";

- Evaluate (explore) the state of subject development, its "reason and affections" level;

- Enhance the efficiency and security of cyberspace interaction in terms of achieving the objectives of knowledge.

Binary logic is good for the IT industry in the aspect of pragmatism, uniqueness. However, the electronic virtual world is the socio-cultural sphere, its electronic projection. Here, binary logic is not only sufficient, but it is dangerous. The negative effects of the robots' (cyborgs) invasion of our world are often being shown. However, there is no less dangerous phenomenon personal consciousness robotics. Therefore, the modal logic should become the electronic virtual world logic (EVWL) - more adequate model of human logic.

Knowledge should not be formalized, entailing consciousness and human mentality technologization. To a certain extent (at the pragmatic level) formalization of knowledge is useful: it leads to the accuracy of the estimates, orderliness, etc. However, the overall technologization of mentality deprives it inborn naturalness, causes straightforwardness and flatness of the evaluations. In cyberspace, as in the socio-cultural milieu, the knowledge must be conveyed in the "motley" color, adequate to its various twists and turns. In other words, the knowledge culture of any person, the subject of education, in particular, must comply with the culture of cyberspace. Therefore, the knowledge culture, or being independent on the shape, content and value, is at the same time, part of an overall human culture, the development and extension of its information culture.

Recently, the technologizing problem of virtual world, cyberspace, and also the human mentality gets great emphasis: "the researchers concluded that the information field of the Internet has had a significant impact on the value-semantic sphere of the person" [4]. In particular, V.A. Pleshakov in [5] says about the need to support human "cyber socialization" and the formation of his or her cyber culture. Consideration of this issue through the prism of modal logic and, consequently, the modal-logical representation of cyberspace will help to better understand its essence and, therefore, find its effective solution.

Apart from the logical value "True" (1) and "False" (0), modalities (modal assessment) are found in modal logic (ML). Most often, it is "Necessary", "Possible" and their opposites: "Casual", "Impossible." Modalities can act as independent logical values in multi-valued logic.

The semantics of the "Necessary" assessment corresponds to the similar concept in philosophy: the necessity is regular and can be expressed in a variety of affections. Affection is chaotic, but expressing the regularity, it has a regular character too. For this reason, necessity is expressed in a formal regularity, which has representation in a closed predicate formula (statement) $\left(\forall x_{1}^{i} \exists x_{i+1}^{n}\right)\left(\mathrm{F}\left(x_{1}^{n}\right)\right)$. Whereas it is a regular ratio, suggesting multiple reproduction, nonvacuous set of variables are found in it under the universal quantifier $\forall$. As regularity, this formula must be true for any state of the system. However manifesting itself at random, the truth of it does not always occur: errors are possible that caused by subjective and other factors. Formally, the formula containing the "Necessary" assessment is true in any state of the system, but each concrete realization can be true only starting at some state.

The "Possible" assessment is determined by the requirements for the system itself, the requirements and the conditions for its environment. Possibility is expressed in accordance with these requirements and 
conditions, as well as in the absence of formal contradictions to the system regularities as its prerequisites. At the formal level the "Possible" assessment is expressed by a closed formula (statement) $\left(\exists \mathbf{x}_{1}^{\mathrm{n}}\right)\left(\mathbf{f}\left(\mathbf{x}_{1}^{\mathrm{n}}\right)\right)$, that semantically means the formula is true in one of the states of the system, or rather, is true, starting with a certain state of the system.

The "Necessary" assessment expresses their inner potential, invariant properties and physical features in the real-world spaces. The "Possible" assessment expresses the socio-cultural conditions, environmental resources, norms of consumption.

In modal logic, the following coincidences are applied. The conjunction of the "Necessary" and "Possible" assessments -the "Possible" assessment: the first is better than the second, "the worst" is chosen. The disjunction of the "Necessary" and "Possible» assessments - the "Necessary" assessment: the "best" is chosen. Accordingly, the conjunction of the "Casual" and "Impossible» assessments - the "Impossible" assessment: the first is worse than the second, the "worst" is chosen. The disjunction of the "Casual" and "Impossible» assessments - the "Impossible" assessment: the "best" is chosen.

Modal expressed knowledge and social culture in active system are necessary for a fruitful interaction with cyberspace, while they themselves develop in the course of this interaction. Cyberspace capabilities and needs do not manifest automatically, but implemented by active system and the environment impossibilities may be overcome, if they have an internal system need under the system relevant performance. The conjunction of several logical expressions (predicative formulas) in modal logic corresponds to each element of the subject and educational cyberspace interaction:

- Expression of the internal state and the interaction system evaluation $-\mathrm{f}$.

- Expression of condition and the external environment assessment (socio-cultural, scientific and educational, activity) - so; environment personal assessment by subjects, expression of its worldview, culture, morality sl. That is, it is the conjunction of two logic (modal) assessments: $\mathrm{s}=\mathrm{so} \wedge \mathrm{sl}$.

Thus, each type of knower, information activities and cyberspace interaction has its own logical formula of its assessment in modal logic: $\mathbf{w}=\mathbf{f} \wedge \wedge \mathbf{s o} \wedge \mathbf{s l}$.

1. The interaction with the electronic educational resources in the field of general education. It is special open-access resources, carried out in accordance with state standards and focused on electronic media or network portals on the Internet. They satisfy the society, social and cultural environment's requirements and conditions. That is, regarding the system intrinsic properties interaction with them must be $-\mathrm{f}=$ «Necessary». In reference to external environment conditions, they and social culture objects, media environment interaction is also necessary - so $=$ «Necessary», because these resources are mandatory or advisory.

Motivation availability, subjects' cognitive interests are assumed to be. Consequently, this subject interaction type can be evaluated as logically required (including the personal factor), $\mathrm{sl}=$ «Necessary», and its common the "w" assessment as "Necessary". Hence the educational media environment extension by introducing and adapting general media milieu resources and their orderly distribution in specialized Internet portals is the optimal and the most perspective.

2. Interaction with the electronic resources of the educational application. This is interaction in selfeducation, in the implementation of individual educational programs (educational trajectory), in the preparation of projects and in professional development. As resources in form and content, they are both physically and logically possible in terms of modal logic. These are media environment objects. The danger of this interaction is that these objects can be resource only in shape but not in substance. The self-study subjects have a general cognitive goal, but do not have the goal of a particular interaction - there is only a problem, the purpose is determined in the interaction course. However, taking into consideration consistency of aim and motivation, the information search logical model is found. The subject is not interested in the information, which does not fit it. That is, the subject filters information, resources. Its information culture, information security culture, a critical attitude toward information is being developed. The subject becomes a carrier and an information culture source.

The derived information and resources accompany this media environment interaction. That is, the capability implementation causes the expansion of personal education media milieu. While it itself (media milieu) causes the extension of media milieu capabilities, its subsequent states. The subject not merely "settles" in cognitive cyberspace, but also adds on it in accordance with the objectives of its self-education.

3. Interaction with media objects with the "Casual" or "Impossible" assessments. As far as the impossible is the casual, this interaction can be viewed as a single type. Because the interaction objects here, in general, are not the resources, then the social environment logical evaluation in relation to them is "Casual" too. Such cooperation in education and self-education is not optimal, but acceptable. For example, when you want to search for a wider cognitive and socio-cultural information on a subject's theme of interest, followed by filtration and sampling of certain features and criteria.

The randomness in this case means that there is no clear objective of this cooperation, and there is no search model for the subject's information of interest. Hence, the result of this search, which is not entirely certain, may be useful, reliable information, located in the media environment resources. However, it is also possible to obtain a different kind of information:

- Not very useful to the subject, unreliable information, distorting the reality.

- Deliberately false and harmful information, having a negative impact on the moral and psychological condition of the subject. 
- Negative information that accompanies the useful information in the context of commercial or other subjective purposes.

Such information is evaluated by sociocultural environment as logically impossible. Nevertheless, to realize this assessment can only be the subject having enough personal information culture. Therefore, this type of interaction is contraindicated to the subject to the unformed information culture, information security culture. However, a complete protection of the subject's cognitive activity from it is impossible in the age of global communication and internet. Moreover, personal information culture can be formed only under conditions of full and self-exposure in the media milieu. Therefore, the information culture development should be started from the beginning of computer science training, rather than leaving it to the end of the course, as envisaged in some textbooks on computer science.

Formation of knowledge, skills, competencies, knowledge and perception culture, information culture of educational subject should go hand in hand and interconnected.

Information culture of the education subject should include the personal safety culture. It is true for all three types of interaction described above. Otherwise, cyberspace itself can be a source of negative psychological impact on the person interacting with it.

Any education subject should start from the real world needs and challenges, the part of which it is, by building its interaction with cyberspace and creating individual subspace in it. In other words, the real world has to be the starting and end point of any interaction with the virtual world, cyberspace.

\section{References}

1. Yu.G. Korotenkov, Computer science and education, Russian Academy of Education, Moscow 4 (2012) [In Rus]

2. Yu.G. Korotenkov, Smart-society and Smarteducation. Materials of the X international scientific and practical conference "Trends of modern science - 2014” (Sheffield, S Yorkshire, England, 2014)

3. Liu Gang, Problems of philosophy, 5 (2007)

4. E.M. Ozhogina, Information and communication technologies' possible applications as a tool for the senior pupils' life orientation development. Modern information technologies in IT education (Moscow State University, Moscow, 2012) [In Rus]

5. V.A. Pleshakov, Theory of person's cyber socialization (Homo Cyberus, Moscow, 2011) [In Rus] 